\title{
Locational marginal prices with SVC in Indian electricity market
}

\author{
A. Kumar $^{1}$, Punit Kumar ${ }^{2}$ \\ ${ }^{1 *}$ Department of Electrical Engineering, National Institute of Technology Kurukshetra, INDIA \\ ${ }^{2}$ Department of Electrical Engineering, National Institute of Technology Kurukshetra, INDIA \\ "Corresponding Author: e-mail: ashwaks@gmail.com, Tel+91-1744-238389, Fax.+91-1744-238050
}

\begin{abstract}
Spot pricing based on short run marginal cost (SRMC) theory has the potential to provide the economic signals for the power system operation. Reactive power has gained importance as an ancillary service in competitive markets and its impact on nodal price can not be ignored. With the emergence of FACTS technology, their role in the marginal price determination should be considered taking their cost function into account. In this paper, the nodal price for real and reactive power considering different reactive power price cost calculation methods for generator reactive power has been presented. The impact of Static Var Compensator has also been considered taking their cost function into account. Mixed integer non-linear programming approach has been formulated for the solution. The proposed approach has been applied for Indian 246-bus NREG system taking bilateral transactions into consideration over and above the pool transactions.
\end{abstract}

Keywords: Real and reactive power pricing, nodal price, cost model, FACTS devices, Pool model, Hybrid model.

\section{Introduction}

The electricity industries all over the world are transforming their electricity busyness into the competitive environment for technological innovations, better choice, lower rates, and better operation of the system. In this environment, transmission price of real and reactive power has become central issue for better and economic operation of system. With the growing interest in determining the costs of ancillary services needed to maintain the quality of supply, the spot price for reactive power has also gained great importance. Many authors have proposed models and approaches for determining spot pricing of real and reactive power. Authors developed the model introducing reactive power pricing and revealed that the Lagrangian multipliers corresponding to node power balance equations in OPF represent the marginal costs of the node power injections (Baughman and Siddiqi, 1993). Many investigations have been carried out for appropriate pricing of reactive power (Dandachi et al 1996, El-Keib, 1997, Li et al, 1993, Chatopadhyaya et al., 1995, Choi et al., 1998, Hao et al., 1997, Muchai et al., 1999, Dona et al., 2001, Gill et al, 2000, Paucar et al, 2001, Rider and Paucar, 2004). El-Keib et al proposed decoupled OPF approach for reactive power cost minimizing active power losses. Chatopadhyaya et al proposed the cost of reactive power investment equipments to be included in an objective function for reactive cost component. Dandachi et al attempted reactive power cost calculation using linear and quadratic cost function of reactive cost of generator minimizing total reactive power cost of generrator. Hao et al proposed methods for reactive power cost calculations and emphasized the use of reactive power services and their cost determination. (Lamont and Fu 1999) proposed opportunity cost concept based on generator's capability curve and a formulation for reactive power cost computation. However, the cost calculation is difficult. Gill et al proposed a cost of generation of reactive power as a function of active power losses of generator. Muchai et al. presented summary of algorithms for the determination of reactive power price (Muchai et al 1999). Recently (Paucar and Rider, 2004) have presented approaches for spot price determination of reactive power.

Flexible AC transmission systems are emerging trends of technology for better operation of the system for more power transfers and utilizing optimally the transmission corridors more flexibly. Their role in transmission pricing has also been presented in the literature. The role of FACTS controllers on transmission pricing have been presented by many authors (Olivera et al, 1999, 
Srivastava and Verma, 2000, Shrestha et al, 2005, Zhao et al, 2005, Cai et al, 2003, Chanana and Kumar, 2006, 2010). Recently (Shrestha and Feng, 2005) presented simulation studies on the effects of TCSC on the spot price of real and reactive power using heuristic method to determine the location of TCSC.

In a deregulated environment, the number of bilateral transactions has grown rapidly. It is required to help the system operator to evaluate their impacts on the system operation. Bilateral transactions between sellers and buyers are deemed to be feasible, if these can be accommodated without the violations of system security limits (Hamoud et al. 2000, Cheng et al, 1998). Authors (Cheng et al, 1998) discussed the secure bilateral transaction matrix determination in deregulated environment utilizing the approach of DC distribution factors. (Kumar, 2007) presented secure bilateral transactions determination in hybrid electricity markets and studied the impact of TCPAR and TCSC on their pattern. AC distribution factors are more accurate compared to the DC distribution factors as assumptions are involved in the determination of DC distribution factors.

In this paper, nodal prices have been determined considering three different reactive cost model for generators' reactive power cost calculations for bilateral market model. The impact of Static Var Compensator (SVC) devices have been incorporated with their cost model. GAMS and MATLAB interfacing has been utilized to model the system with non-linear equations considering DICOPT model in GAMS (GAMS Cor. USA, 2001, MATLAB and GAMS interfacing, 1999). The comparison has been given for different reactive cost models for NREG 246-bus Indian Power System.

\section{Electricity ACT 2003 and Indian Electricity Market Growth}

With the introduction of competitive electricity markets all over the world, this has great impact on the Indian electricity industry as well. Before electricity act 2003, power system was owned, operated, and managed by the state electricity boards. Few private electricity companies also exist in Bombay, Calcutta, and Ahmedabad. In 1975, central government, through central public sector undertakings like National Hydro Power Corporation (NHPC), National Thermal Power Corporation (NTPC), Damoder Valley Power Corporation (DMC) etc. also entered in the field of generation and transmission to cater the need of power deficit in many states. The need for restructuring the electricity sector was felt in late $80 \mathrm{~s}$, firstly, due to limited resources available with central and state governments and secondly, to improve the technical and commercial efficiency. For catering the need of power, the private sector participation was allowed in 1991 to feed the power generation and subsequently the power transmission was also opened-up to private participation in 1998. Electricity Regulatory Commission Act was enacted in 1998 for establishing regulatory commissions.

With the introduction of The Electricity Act, 2003, with the key features of No techno-economic clearance for generating stations and no state licensing, non-discriminatory and open access to the transmission system, major role for regulators, SERCs and CERC in licensing, tariff, grid rules, and access rules, Provides for power trading, and the eventual creation of a spot market etc. emphasizes competition in power sector. The initial steps for restructuring process have already been taken and accordingly, PGCIL has been notified as central transmission utility at the national level and the SEBs or the main transmission companies in the restructured states are functioning as state transmission utilities at the state level. With the implementation of ACT 2003, many states like Orrisa as a pioneering state in restructuring its utility, other states like Haryana, Maharashtra, Rajasthan, Punjab, Andhra etc. started restructuring their electricity busyness with the introduction of competition in the distribution side. The process of restructuring is progressing well and conceptual model of regional and state whole electricity market models were proposed by (Singh and Srivastava, 2004). A national power exchange as a Day-a-head (DA) balancing market for inter regional trades was proposed for Indian electricity market by (Bajpai and Singh, 2006). This power exchange (PX) acts like a national Whole-sale electricity market with a uniform price double auction mechanism for market clearing process. The authors (Bajpai and Singh, 2006) proposed a simplified and theoretical model for national power market with commercial and physical transactions with a PX getting information of Available Transfer Capability (ATC) from National Load Dispatch Centers (NLDC) on DA basis to dispatch the generation based on load requirements. Ancillary service mechanism for better operation of the Indian Electricity market is also gaining importance and author in (Parida et al, 2009) proposed frequency regulation service as capacity linked mechanism with pros and cons with the existing FGMO based FR mechanism. An ancillary service model has been proposed for Indian Power Market scenario in (Parida, 2009).

\section{Mathematical Model of Bilateral Transactions}

A PoolCo is defined as a centralized market place that clears the market for the buyers and sellers. Electric power sellers/buyers submit bids to the pool for the amount of power that they are willing to trade in the market. Thus, under this model, one single entity, the Pool Company (usually system operator), purchases the power from the competing generators in the open market and generally sells it at a single market clearing price to the retailers/or consumers. Sellers in a power market would compete for the right to supply energy to the grid, and not to specific customers. In this market, low cost generators would especially be rewarded.

In a deregulated electricity market structure, under competition and open access, the different transactions may take place directly between buyers and sellers. A bilateral transaction is an exchange of power between buying and selling entities. These transactions 
can be defined for a particular time interval of the day and its value may be time varying. It may be either firm or non-firm and can be a short term and long-term transaction.

The bilateral contract model may include different kinds of transactions as:

Bilateral Transactions: A bilateral transaction is made directly between a GENCO and a DISCO without any third party intervention.

Multilateral Transactions: A multilateral transactions is a trade arranged by energy brokers and involves more than two parties. Multilateral transactions are the extension of bilateral transactions and may take place between a group of sellers and a group of buyers at different nodes.

Ancillary Services Transactions: The SO may directly make some transactions with some GENCO in order to provide essential ancillary services for system regulation. The conceptual model of bilateral dispatch is that sellers and buyers enter in to transactions where the quantities traded and the trade prices are at the discretion of these parties and not a matter of ISO. These transactions are then brought to the ISO with a request that transmission facilities for the relevant amount of power be provided. If there is no violation of static and dynamic security, the ISO simply dispatches all requested transactions and charges for the service.

The bilateral concept can be generalized to the multi-node case where the seller, for example a generation company called gencos, may inject power at several nodes and the buyer bus called discos also draw load at several nodes. Unlike pool dispatch, there will be a transaction power balance in that the aggregate injection equals the aggregate draw off for each transaction.the bilateral contract model used in this paper is basically a subset of the full transaction matrix proposed in (Hamoud et al, 2000). In its general form, the transaction matrix $t$ as shown in (1) is a collection of all possible transactions between generation (g), demand (d), and any other trading entities (e) such as the marketers and the brokers.

$T=\left[\begin{array}{ccc}G G & G D & G E \\ D G & D D & D E \\ E G & E D & E E\end{array}\right]$

In present paper, all transactions are assumed between the suppliers $(\mathrm{G})$ and consumers (D). It is also noted that the diagonal block matrices (GG and DD) are zero because it is assumed that there are no contracts made between two suppliers or two consumers. Neglecting transmission losses, the transaction matrix can be simplified as:

$T \equiv[G D]=\left[D G^{T}\right]$

Each element of $t$, namely $t_{i j}$, represents a bilateral contract between a supplier $\left(p_{g i}\right)$ of row $i$ with a consumer $\left(p_{d j}\right)$ of column $j$. Furthermore, the sum of row $i$ represents the total power produced by generator $i$ and the sum of column $j$ represents the total power consumed at load $j$.

$T \equiv\left[\begin{array}{lll}t_{1,1} & \ldots & t_{1, n d} \\ t_{2,1} & \ldots & t_{2, n d} \\ t_{n g, 1} & \ldots & t_{n g, n d}\end{array}\right]$

Where:

$N_{g}=$ number of generators, and $n_{d}=$ number of loads.

In general, the conventional load flow variables, generation $\left(P_{g}\right)$ and load $\left(P_{d}\right)$ vectors, are now expanded into two dimensional transaction matrix $t$ as given in (4).

$\left[\begin{array}{l}P_{d} \\ P_{g}\end{array}\right]=\left[\begin{array}{ll}T^{T} & 0 \\ 0 & T\end{array}\right]\left[\begin{array}{l}u_{g} \\ u_{d}\end{array}\right]$

Vector $u_{g}$ and $u_{d}$ are column vectors of ones with the dimensions of $n_{g}$ and $n_{d}$ respectively. There are some intrinsic properties associated with this transaction matrix $T$ (Cheng et al. 1998). These are column rule, row rule, range rule, and flow rule. These properties have been explained in (Cheng et al, 1998). Each contract has to range from zero to a maximum allowable value, $T_{i j}^{\max }$. This maximum value is bounded by the value of corresponding $P_{g i}{ }^{m a x}$ or $P_{d j}$ whichever is smaller. The range rule satisfies:

$$
0 \leq T_{i j} \leq T_{i j}^{\max } \leq \min \left(P_{g i}^{\max }, P_{d j}\right)
$$

It is also possible for some contracts to be firm so that $T_{i j}{ }^{0}$ is equal to $T_{i j}{ }^{m a x}$. According to flow rule the line flows of the network in ac model can be expressed as follows:

$$
P_{\text {line }}=D F\left[P_{g}-P_{d}\right]
$$

The matrix $D F$ is the distribution factors matrix and have been determined with AC load flow approach (Kumar, 2009). If the representations of the $P_{g}$ and $P_{d}$ are substituted by using the definition of $T$ as given in (4), the line flows can be expressed in an alternative as follows: 
$P_{\text {line }}=D F\left[T-T^{T}\right]\left[\begin{array}{l}1 \\ \vdots \\ 1\end{array}\right]$

$$
G D_{s b}^{\max }=\min \left(P_{G B, s b}^{\max }, P_{D B, b b}\right)
$$

Bilateral transactions in per unit for 246 bus NREG system has been assumed as:

$\mathrm{GD}(1,240)=1.5 ; \mathrm{GD}(1,245)=1.0$;

$\operatorname{GD}(1,120)=0.2 ; \mathrm{GD}(1,130)=0.3$;

$\mathrm{GD}(24,190)=1.2 ; \mathrm{GD}(24,200)=1.0$;

The values of transactions are in p.u. and are considered as additional transactions over and above the pool transactions already committed. The hybrid model combines various features of the previous two models. In the hybrid model, the utilization of the PoolCo is not obligatory, and any customer would be allowed to negotiate a power supply agreement directly with the suppliers or choose to accept power at the pool market price. In this model, PoolCo will serve all participants (buyers and sellers), who choose not to sign bilateral contracts. However, allowing customers to negotiate power purchase agreements with suppliers would offer a true customer choice and an impetus for creation of wide variety of services and the pricing options to best meet individual customer needs.

\section{Cost Model of SVC and its Optimal Location}

The cost functions for SVC have been taken as follows (Cai et al, 2003): SVC:

$$
\operatorname{Cost}(F)=0.0003 S^{2}-0.3051 S+127.38 \$ / \mathrm{KVAR}
$$

$\mathrm{S}$ is the operating range of the FACTS devices in MVar. The unit for generation cost is US\$/Hour and for the investment costs of FACTS devices are in US\$. They must be unified into US\$/Hour. Normally, the FACTS devices will be in-service for many years. However, only a part of its lifetime is employed to regulate the power flow. In this paper, five years is applied to evaluate the cost function. Therefore the average value of the investment costs is calculated using the following equation:

$$
c_{1}(f)=\frac{c(f)}{8760 * 5} \$ / \mathrm{hr}
$$

where $c(\mathrm{f})$ is the total investment costs of FACTS devices.

\section{A. Optimal Location of SVC}

Flexible AC transmission system devices usage in the present day transmission system has become imperative for better operation and control of the system. In the deregulated environment, for the competition to become viable, it is essential that the existing structure be utilized optimally, economically, and efficiently. This has necessitated the potential of FACTS devices controlling the power flow pattern of the system. These FACTS devices are costly and their location in the system has to be justified. There are many approaches to find the optimal location of FACTS devices like loss sensitivity index, line power flow based sensitivity index with respect to FACTS parameters, performance based index, and price based index. Many authors have developed techniques for their optimal location (Singh and David, 2000, Singh et al, 2001). Some of the authors utilized the concept of flow sensitivity approach and performance based index approach for the optimal location of these devices (Singh and David, 2000).

In this work, two approaches have been utilized for finding an optimal location of SVC. In the first approach, reactive power price zones have been determined. Based on the reactive power price zones, the zone with high variation of reactive power nodal price can be identified. The zone with the higher variations in reactive power nodal price can be selected for SVC placement. Now the reactive power price index which has been taken as a ratio of reactive power nodal price at a bus to the total reactive power price of the system can be determined at each bus for the most sensitive zone. The bus lying in the sensitive zone with a higher price index can be identified for placement of SVC. In the second approach, mixed integer programming based approach has been utilized to decide the best place for SVC. The DICOPT solver of GAMS has been utilized to solve the problem with integer variable either 1 or 0 showing the presence or absence of SVC in the system. In this case, integer variable has been introduced in an objective function with the cost of SVC, equality constraint of reactive power injection and inequality constraints for reactive support of SVC within upper and lower limits and number of SVCs. The bus number 155 has been selected for optimal location of SVC in the present work. It is also observed from the Fig. 3 for reactive power nodal price that the reactive power price at bus 155 is quite high. Although the price is also high at bus 240, however, only one SVC has been considered for studying the impact of SVC on real and reactive power price of the system. 


\section{Mathematical Model for Locational Marginal Price Determination}

The real and reactive power nodal prices, fuel cost, cost components of reactive power with different FACTS devices have been obtained solving an optimization problem of minimizing total cost subject to equality and inequality constraints for a pool model based electricity market.

The general form of the problem formulation can be represented as.

Min $F\left(x, u, p, \xi^{\text {int }}\right)$

Subject to equality and inequality constraints defined as

$h\left(x, u, p, \xi^{\text {int }}\right)=0$

$g\left(x, u, p, \xi^{\text {int }}\right) \leq 0$

where,

$x$ is state vector of variables $V, \delta$;

$u$ are the control parameters, $P_{g i}, Q_{g i}$;

$p$ are the fixed parameters $P_{d i}, P_{D B}, P_{D P}, Q_{d}$,

$\xi^{\text {int }}$ is the integer variable and values 1 or 0 represents presence or absence of the FACTS device.

The objective function can be represented as:

(a) Objective function

$$
\sum \operatorname{Cost}\left(P_{i}\right)+\operatorname{Cost}\left(Q_{i}\right)+\xi_{S V C i} * \operatorname{Cost}\left(F_{i}\right)
$$

The objective function consist three cost components as cost of real power, cost of reactive power, and cost of FACTS devices. These can be represented as:

$\operatorname{Cost}\left(\mathrm{P}_{\mathrm{i}}\right)=$ Cost function of real power for $\mathrm{NG}$ (no. of generators)

$\operatorname{Cost}\left(\mathrm{Q}_{\mathrm{i}}\right)=$ Cost function of reactive power for set of $\mathrm{NG}$ generators.

$\operatorname{Cost}\left(\mathrm{F}_{\mathrm{i}}\right)=$ Cost function of FACTS device (SVC).

Where:

$$
\operatorname{Cost}\left(P_{i}\right)=a_{p} P_{i}^{2}+b_{p} P_{i}+c_{p} \$ / h
$$

The cost of reactive power produced by a generator is essentially composed of two components: fixed costs or investment costs and variable costs. Variable cost in turn consists of operating costs (including fuel and maintenance cost) and the opportunity cost which is imposed on the generator resulting from reduction of its active power generation. Three methods have been considered to evaluate the cost of reactive power of generators.

\section{A. Triangular approach (Method-1)}

The triangular approach method of reactive power cost calculation for generators is essentially based on the formulation for active power cost, in which the active power is replaced by reactive power using the triangular relationship using power triangle. This cost function can be represented as:

$$
\operatorname{Cost}(Q)=a^{\prime \prime} Q^{2}+b^{\prime \prime} Q+c^{\prime \prime} \$ / \mathrm{hr}
$$

where, $a$ ", $b$ ", $c$ " are constants depending on power factor $(\cos \theta)$ and are calculated as follows from power triangle (Zhao et al, 2005)

$a^{\prime \prime}=a_{p} \sin 2 \theta$

$b^{\prime \prime}=b_{p} \sin \theta$

$c^{\prime \prime}=c_{p}$

\section{B. Maximum real power based approach (Method-2)}

If $\left(P_{\max }\right)$ is a maximum active power produced from a generator, then its cost for generating active power equals cost for $\left(P_{\max }\right)$. In such a situation, no reactive power is produced and therefore, $\mathrm{S}$ equals $P_{\max }$. Reactive power demanded from a generator will reduce its capability to produce active power. Hence, reactive power produced by generator will result in reduction of its active power production. To generate reactive power $Q i$ by generator $i$ which has been operating at its nominal power $\left(P_{\max }\right)$, it is required to reduce its active power to $P_{\mathrm{i}}$ such that:

$$
P_{i}=\sqrt{P_{\max }^{2}-Q_{i}^{2}}, \Delta P=P_{\max }-P_{i}
$$

$\Delta P$ represents the amount of active power that will be reduced as a result of generating reactive power. To accurately calculate the cost of reactive power $Q i$, we should include all the costs imposed on generator as below:

$\operatorname{Cost}\left(P_{\max }\right)$ : cost of producing active power equal to $P_{\max }$ in one hour.

$\operatorname{Cost}\left(P_{\max }-\Delta P\right):$ cost of generator when producing both active and reactive power with the amounts $P_{\mathrm{i}}$ and $Q_{i}$, respectively. 
$\operatorname{Cost}\left(P_{\max }\right)-\operatorname{Cost}\left(P_{\max }-\Delta P\right): \operatorname{cost}$ of active power reduction due to compulsory reduction in active power generation $(\Delta P)$ for generating reactive power with the amount of $Q i$. This represents the cost of reactive power production while the operating point of generator is changed. The capability curve of generator is shown in Fig.1.

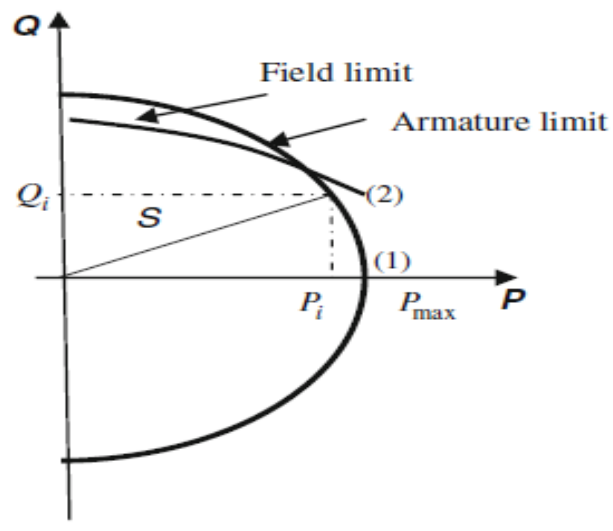

Figure 1. Capability curve of generator

This cost of reactive power production with the operating point of generator moved from point 1 to point 2 as given in Fig. 1 is given as:

$\operatorname{Cost}\left(P_{\max }\right)-\operatorname{Cost}\left(P_{\max }-\Delta P\right)=\operatorname{Cost}\left(Q_{\mathrm{i}}\right)+\Delta P / P_{\max } \operatorname{Cost}\left(P_{\max }\right)$

where, $\left(\Delta P / P_{\max }\right) \operatorname{Cost}\left(P_{\max }\right)$ is related to the change of operating point (In fact this represents the cost of $\Delta P$ MWh energy when the generator is generating its nominal power). Therefore, from the above equations, the cost of reactive component can be represented as:

$$
\begin{aligned}
& \operatorname{Cost}(Q i)=\operatorname{Cost}\left(P_{\max }\right)-\operatorname{Cost}\left(P_{\max }-P_{\mathrm{i}}\right)-\left(\Delta P / P_{\max }\right) \operatorname{Cost}\left(\mathrm{P}_{\max }\right) \\
& \operatorname{Cost}\left(Q_{i}\right)=\frac{P_{\max }-\Delta P}{P_{\max }} \operatorname{Cost}\left(P_{\max }\right)-\operatorname{Cost}\left(P_{\max }-P_{i}\right) \$ / \mathrm{hr}
\end{aligned}
$$

\section{Maximum apparent power based approach (Method-3)}

Synchronous generators are rated in terms of the maximum MVA output at a specified voltage and power factor (usually 0.85 or 0.9 lagging) which they can carry continuously without overheating. The active power output is limited by the prime mover capability to a value within the MVA rating. The continuous reactive power output capability is limited by three considerations: armature current limit, field current limit, and end region heating limit. The reactive power production cost of generator is called opportunity cost reactive power output may reduce active power output capacity of generators which can at least serve as spinning reserve, therefore causes implicit financial loss to generators. Actually, opportunity cost depends on the real-time balance between demand and supply in the market, so it is difficult to determine the real value. The capability curve of generator can be taken to determine the cost of reactive power as a lost opportunity cost from the Fig.2 shown below:

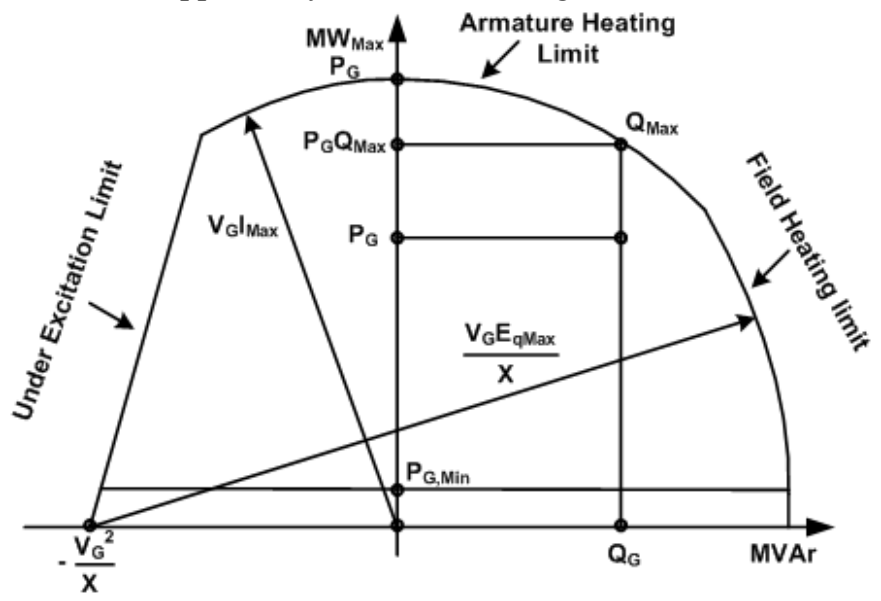

Figure 2. Capability curve of synchronous generator

The opportunity cost component of generator for producing the reactive power can be approximately as (Dai et al 2000):

$$
\operatorname{Cost}\left(Q_{G i}\right)=\operatorname{Cost}\left(S_{G \max }\right)-\sqrt{\operatorname{Cost}\left(S_{G \max }^{2}-Q_{G i}^{2}\right)} * k(\$ / \mathrm{h})
$$


where $S_{G i, m a x}$ is the nominal apparent power of the generator at bus i; $Q_{G i}$ is the reactive power output of the generator at bus i; $K$ is the profit rate of active power generation, usually between $5 \%$ and $10 \% \mathrm{~K}$ is considered as $10 \%$ in the paper work.

(b) Equality constraints: Power flow equations:

The real and reactive power flow equations from bus- $i$ to bus- $j$ can be written as:

$$
\begin{aligned}
& P_{i j}=V_{i}^{2} G_{i j}-V_{i} V_{j}\left(G_{i j} \cos \delta_{i j}+B_{i j} \sin \delta_{i j}\right) \\
& Q_{i j}=-V_{i}^{2}\left(B_{i j}+B_{s h}\right)-V_{i} V_{j}\left(G_{i j} \sin \delta_{i j}-B_{i j} \cos \delta_{i j}\right)
\end{aligned}
$$

The real and reactive power flow equations from bus- $j$ to bus- $i$ can be written as:

$$
\begin{aligned}
& P_{j i}=V_{j}^{2} G_{i j}-V_{i} V_{j}\left(G_{i j} \cos \delta_{i j}-B_{i j} \sin \delta_{i j}\right) \\
& Q_{j i}=-V_{j}^{2}\left(B_{i j}+B_{s h}\right)+V_{i} V_{j}\left(G_{i j} \sin \delta_{i j}+B_{i j} \cos \delta_{i j}\right)
\end{aligned}
$$

(c) Power Injection at buses

subject to following set of constraints

$$
\begin{array}{ll}
P_{g i}-P_{d i}=P_{i} & \forall i \in N B \\
Q_{g i}+\xi_{S V C i} * Q_{S V C i}-Q_{d i}=Q_{i} & \forall i \in N B \\
P_{i}=\sum_{i j \in F B i} P_{i j}-\sum_{i j \in T B i} P_{j i} & \forall i \in N B \\
Q_{i}=\sum_{i j \in F B i} Q_{i j}-\sum_{i j \in T B i} Q_{j i} & \forall i \in N B
\end{array}
$$

(d) Power generating limits

$$
\begin{aligned}
& P_{g i \text { min }} \leq P_{g i} \leq P_{g i \text { max }} \\
& Q_{g i \text { min }} \leq Q_{g i} \leq Q_{g i \text { max }}
\end{aligned}
$$

(e) Power Balance equation

$$
\begin{aligned}
& \sum_{i=1}^{N g} P_{g i}-P_{d i}-P_{\text {loss }}=0 \\
& \sum_{i=1}^{N g} Q_{g i}-Q_{d i}-Q_{l o s s}=0
\end{aligned}
$$

(e) Transmission limits

$$
P_{i j \text { min }} \leq P_{i j} \leq P i_{j \text { max }}
$$

(f) Voltage limits

$V_{i \text { min }} \leq V_{i} \leq V_{i \text { max }}$

(g) Phase angle limits

$\delta_{i \text { min }} \leq \delta_{i} \leq \delta_{i \text { max }}$

(h) Reactive Power Capability Curves limit

$$
P_{g}^{2}+Q_{g}^{2} \leq\left(V_{t} I_{a}\right)^{2}
$$

(i) Equality constraints for bilateral transactions

$$
\begin{aligned}
& \mathbf{P}_{D B}=\sum_{i \in s b} G D_{i j} \\
& \mathbf{P}_{G B}=\sum_{j \in b b} G D_{i j} \\
& \mathbf{P}_{\mathbf{g}}=\mathbf{P}_{G B}+\mathbf{P}_{G P} \\
& \mathbf{P}_{\mathbf{d}}=\mathbf{P}_{D B}+\mathbf{P}_{D P} \\
& \mathbf{P}_{\mathbf{f b}}=D F\left(\mathbf{P}_{G B}-\mathbf{P}_{D B}\right) \\
& \mathbf{P}_{\mathbf{f p}}=D F\left(\mathbf{P}_{G P}-\mathbf{P}_{D P}\right) \\
& \boldsymbol{P}_{\boldsymbol{f}}=\boldsymbol{P}_{\boldsymbol{f b}}+\boldsymbol{P}_{f \mathfrak{p}}
\end{aligned}
$$


$G D_{s b}^{\max }=\min \left(P_{G B, s b}^{\max }, P_{D B, b b}\right)$

(j) limit on FACTS controller svc

$\sum_{S V C i} \xi_{S V C i} \leq N_{S V C i}^{\max }$

(k) Limit on FACTS controller SVC

$u_{r i} * Q_{S V C i} \leq Q_{S V C i} \leq u_{r i} * Q_{S V C i}^{\max }$

Where $u_{r i}=\{0,1\}$ is a binary variable defining presence or absence of SVC.

Where GD $=$ bilateral transaction matrix

$\mathrm{P}_{\mathrm{DB}}=$ vector of bilateral demand

$\mathrm{P}_{\mathrm{DP}}=$ vector of pool demand

$\mathrm{P}_{\mathrm{GB}}=$ vector of bilateral generation

$\mathrm{P}_{\mathrm{GP}}=$ vector of pool generation

$s$ and $b$ are the sets of the seller and buyer buses, respectively.

The nodal prices can be obtained formulating Lagrange function as:

$L(\underline{x}, \underline{\lambda}, \underline{\mu})=f(\underline{x})+\sum_{k=1}^{m} \lambda_{k} h_{k}(\underline{x})+\sum_{j=1}^{p} \mu_{j} g_{j}(\underline{x})$

And the minimum point $\underline{x}^{*}$ satisfies

$\left.\frac{\partial L}{\partial x_{i}}\right|_{\underline{x^{*}}, \underline{\lambda}^{*}, \underline{\mu}^{*}}=0$
$\left.\frac{\partial L}{\partial \lambda_{i}}\right|_{\underline{x}^{*}, \underline{\lambda}^{*}, \underline{\mu^{*}}}=0$
$\left.\frac{\partial L}{\partial \mu_{i}}\right|_{\underline{x}^{*}, \underline{\lambda}^{*}, \underline{\underline{\mu}}^{*}}=0, \quad \mu \geq 0 \quad$ if $\quad g_{j}\left(\underline{x}^{*}\right)=0$
and $\mu_{i}=0$ if $\quad g_{j}\left(\underline{x}^{*}\right)<0$

$\underline{x}^{*}, \underline{\lambda}^{*}, \underline{\mu} *$ are the vector of state variables, vector of Lagrange multipliers for each equality constraints, and vector of Lagrange multipliers for each inequality constraints.

Note that $\mu \geq 0$ in (58) that inequality constraint will be active only if gradients of the function and the constraint are opposite:

$(\nabla f)^{T} \nabla g \leq 0 \Rightarrow \mu \geq 0$

The derivative term of Lagrange w.r.t real power and reactive power are called the marginal cost of real and reactive power defined as:

Marginal cost of real power:

$\lambda_{P}=\frac{\partial L}{\partial P_{g}}=0$

Marginal cost of reactive power

$\lambda_{Q}=\frac{\partial L}{\partial Q_{g}}=0$

The optimization problem is solved using the GAMS 21.3 / DICOPT solver and utilizing interfacing with MATLAB 6.5.

\section{Results and Discussions}

The results have been determined for NREG 246 bus system. The results have been determined without and with FACTS devices considering the different methods of reactive power cost model. The results have been obtained for different cases as follows-

Case 1: Results without FACTS devices for all methods

Case 2: Results with FACTS device (SVC) for all methods

\section{A. Results for NREG-246 bus System}


(Case-1): The results of the marginal cost for real and reactive power for Case 1 using different methods of reactive power model is shown in Figs. 3 to 5.

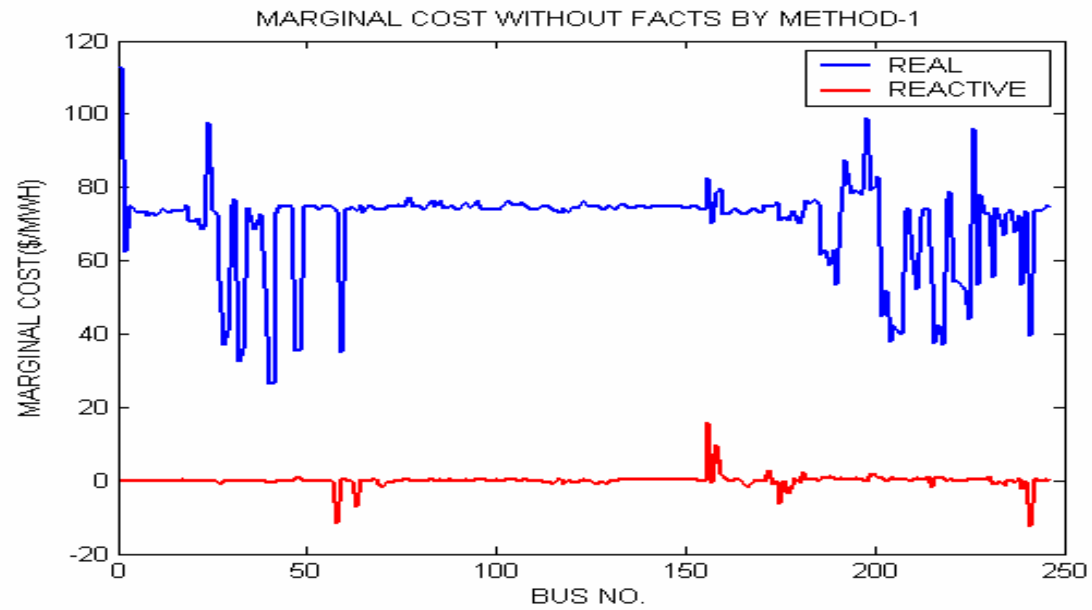

Figure 3. Marginal Cost of real and reactive power without any FACTS device (Method-1)

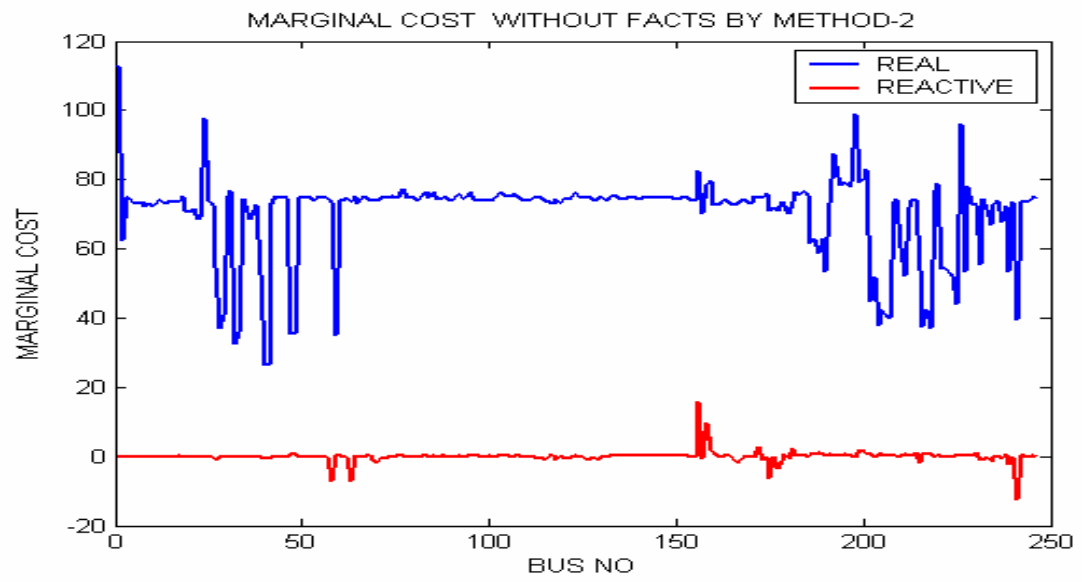

Figure 4. Marginal Cost of real and reactive power without any FACTS device (Method-2)

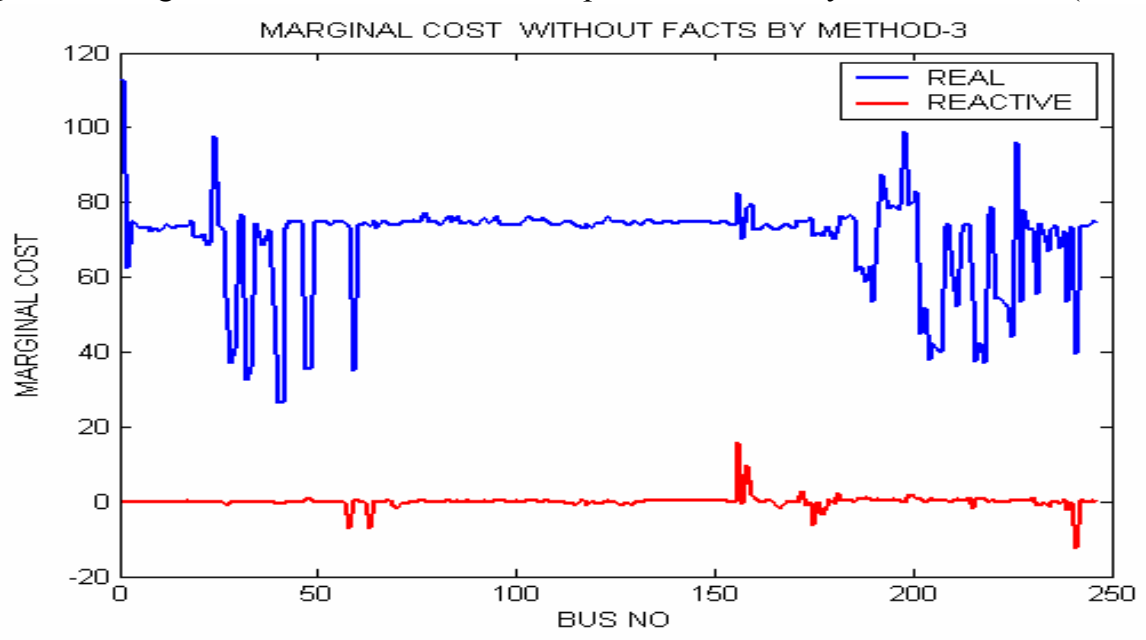

Figure 5. Marginal Cost of real and reactive power without any FACTS device (Method-3)

It is observed from Fig. 3 to Fig. 5 that the Marginal Cost at Bus-1 is observed higher and for bilateral transaction model the nodal prices are found lesser than pool model. The Reactive Power Marginal Costs are both positive and negative. It is observed from the figures that variation in real power price is high corresponding to 1 to 60 buses and 160 to 296 buses. Similar observations are found for reactive power nodal price. The nodal price variation is small for buses 60 to 160 . The reactive power nodal price variation is more only at few buses and for most of the buses the reactive power marginal price is near zero. It is 
observed from the table that reactive power cost component is lowest for method 3 and fuel cost is found to be higher for method 2. The overall cost is found same for method 1 and method 3 .

Table 1. Results for NREG 246- bus system for case-1

\begin{tabular}{|l|l|l|l|}
\hline & Method-1 & Method -2 & Method -3 \\
\hline Fuel cost $(\$ / \mathrm{h})$ & 487073.865 & 566916.437 & 549614.011 \\
\hline Q cost $(\$ / \mathrm{h})$ & 66382.993 & 13459.579 & 3842.847 \\
\hline Total cost $(\$ / \mathrm{h})$ & 553456.859 & $580,376.02$ & 553456.859 \\
\hline
\end{tabular}

(Case-2): The results of the marginal cost for real and reactive power for Case 2 is shown in Fig. 6 to 8.

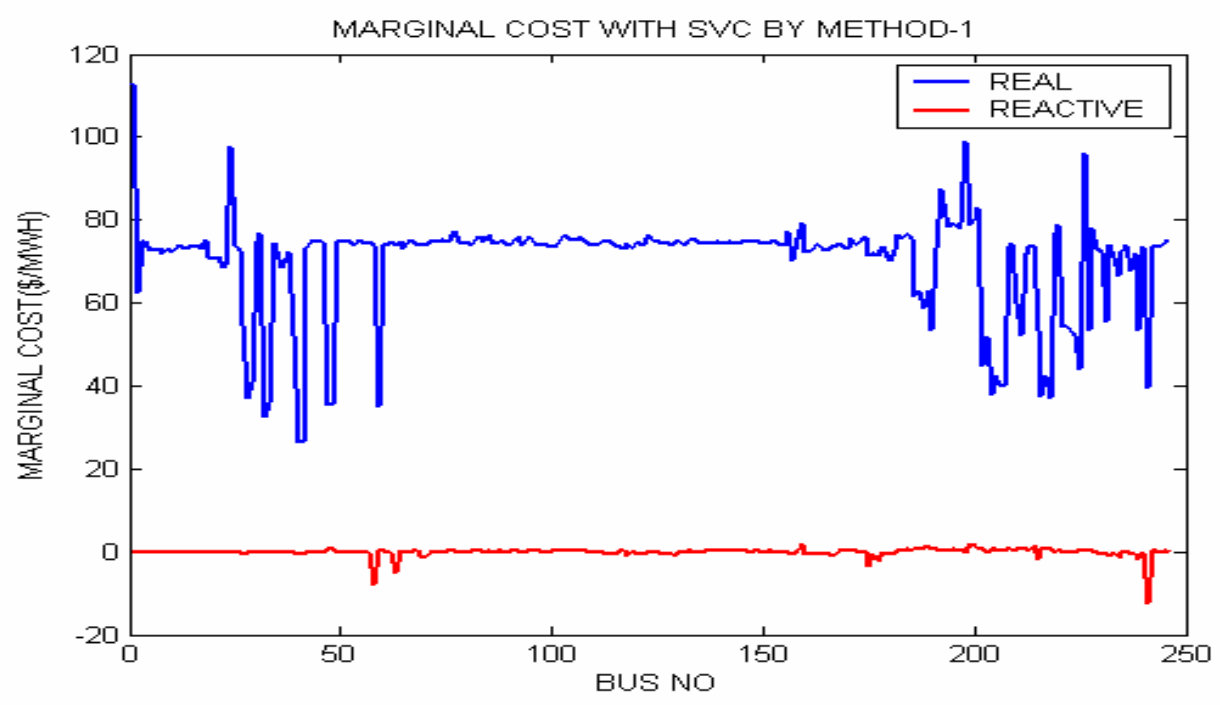

Figure 6. Marginal Cost of real and reactive power with SVC (Method-1)

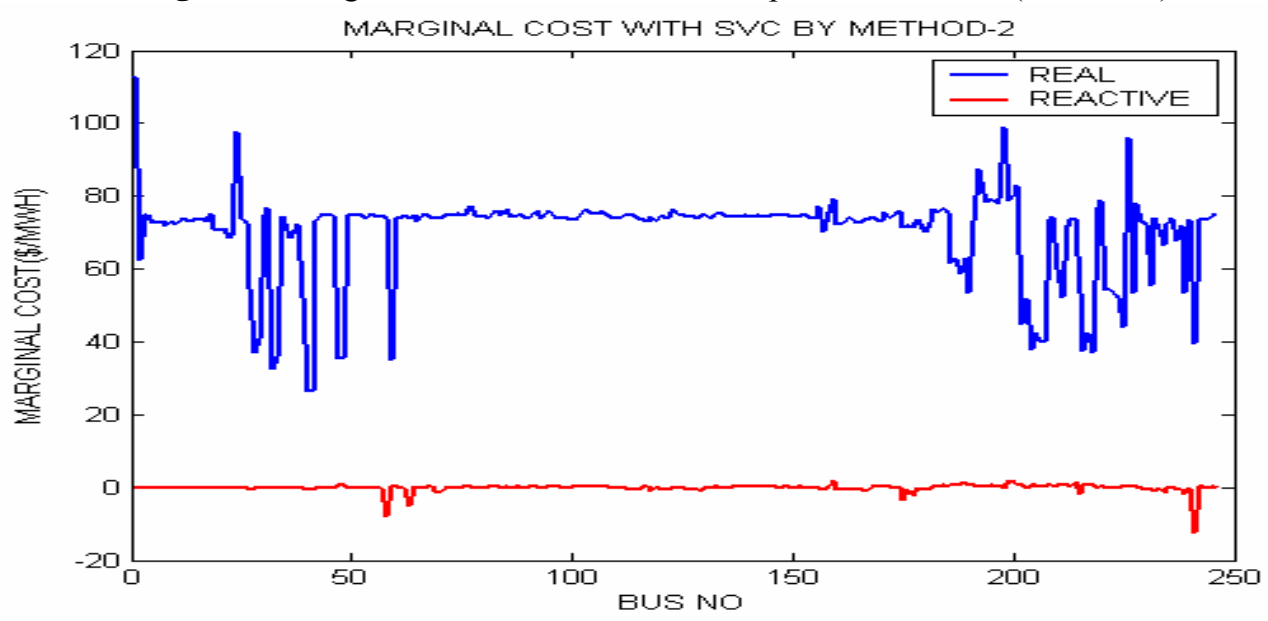

Figure 7. Marginal Cost of real and reactive power with SVC (Method-2) 


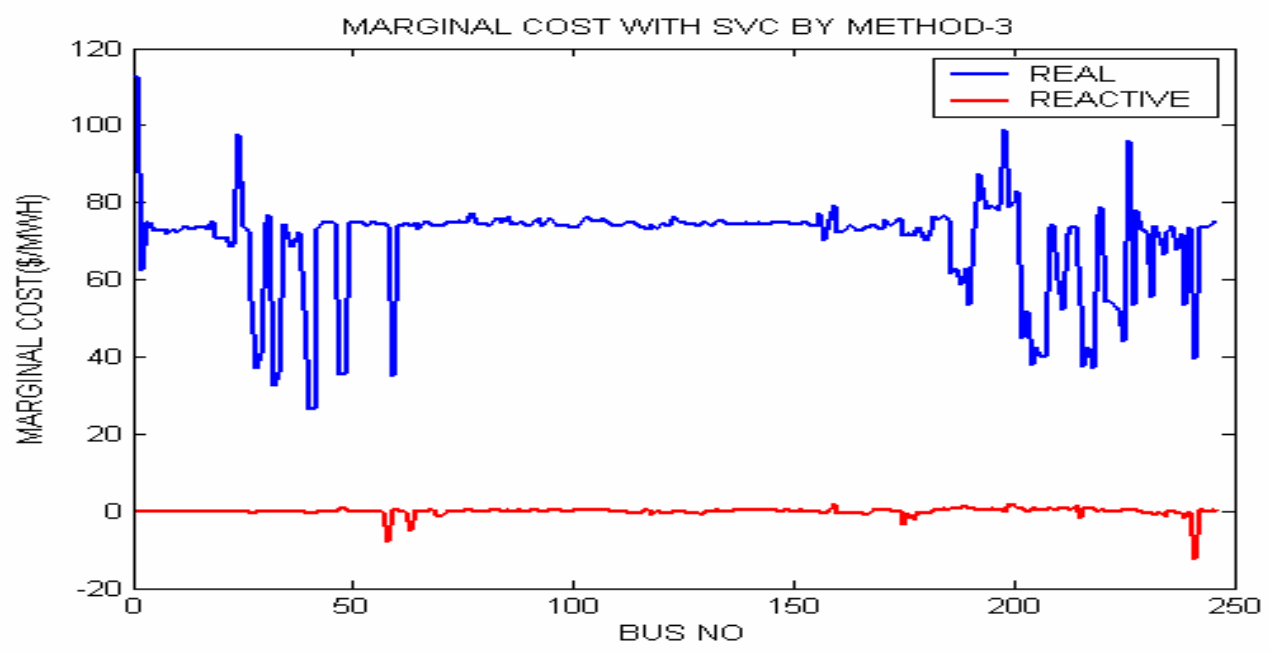

Figure 8. Marginal Cost of real and reactive power with SVC (Method-3)

It is observed from Fig. 6 to 8 that that Marginal Cost from all the three methods is similar. The Marginal Cost at Bus- 1 is maximum and its value is $112.85 \$ \mathrm{MWh}$ and due to Bilateral transaction the nodal prices are lesser than pool model. The Reactive Power Marginal Costs are both positive and negative. It is observed from the figures that variation in real power price is high corresponding to 1 to 60 buses and 160 to 296 buses. Similar observations are found for reactive power nodal price. The nodal price variation is small for buses 60 to 160 . The reactive power nodal price variation is more only at few buses and for most of the buses, the reactive power marginal price is near zero. The above table represents the total Fuel Cost, the reactive power cost and cost of SVC by all three methods of reactive power pricing. It is observed that the reactive power cost component is higher for method 1 and lowest for method 3. The cost component of SVC is same for method 1 and method 2. The total cost is almost same for method 1 and method 3 .

Table 2. Results for NREG-246 bus system (Case-2)

\begin{tabular}{|l|l|l|l|}
\hline & Method-1 & Method -2 & Method -3 \\
\hline Fuel cost $(\$ / \mathrm{h})$ & 486930.341 & 566796.083 & 549234.402 \\
\hline Q-cost $(\$ / \mathrm{h})$ & 66390.411 & 13475.330 & 4060.225 \\
\hline Cost of SVC $(\$ / \mathrm{h})$ & 2.425 & 2.425 & 4.340 \\
\hline Total cost $(\$ / \mathrm{h})$ & 553323.177 & 580273.84 & 553298.968 \\
\hline
\end{tabular}

\section{Comparison of Marginal Cost of Real and Reactive Power at few buses for Pool and Bilateral Model}

The results of marginal prices of real and reactive power for pool model have also been determined utilizing the three different methods of reactive power cost computations of reactive power cost of generator. The fuel cost for pool model obtained with all the three methods are given in Table III. The fuel cost obtained with SVC for pool model is also computed and are given in Table IV.

Table 3. Results for NREG-246 bus system (Case-1)

\begin{tabular}{|l|c|c|c|}
\hline & Method-1 & Method -2 & Method -3 \\
\hline Fuel cost $(\$ / \mathrm{h})$ & 481397.156 & 560275.521 & 543918.169 \\
\hline Q-cost $(\$ / \mathrm{h})$ & 66397.869 & 12480.496 & 3876.856 \\
\hline Total cost $(\$ / \mathrm{h})$ & 547795.025 & 572756.02 & 547795.025 \\
\hline
\end{tabular}

Table 4. Results for NREG-246 bus system (Case-2)

\begin{tabular}{|l|l|l|l|}
\hline & Method-1 & Method -2 & Method -3 \\
\hline Fuel cost $(\$ / \mathrm{h})$ & 481242.782 & 559909.954 & 543989.879 \\
\hline Q-cost $(\$ / \mathrm{h})$ & 66398.864 & 12533.673 & 3651.767 \\
\hline $\begin{array}{l}\text { Cost of SVC } \\
(\$ / \mathrm{h})\end{array}$ & 2.330 & 5.785 & 2.330 \\
\hline Total cost $(\$ / \mathrm{h})$ & 547643.976 & 570295.79 & 547643.976 \\
\hline
\end{tabular}


It is observed that the fuel cost is obtained lower for method-1 for both the cases. The cost reduces with the presence of SVC in the system due to the reactive support provided by the SVC and helping the proper reactive power deployment improving the voltage profile and reducing the losses in the system. The cost of reactive power support from the generators is also obtained minimum for method-3. The overall cost is found lower for method-1 for both the cases. The cost of SVC for supporting reactive power is also obtained minimum for method-1 and method-3.

Comparing the cost with hybrid model, it is observed that the fuel cost is higher with bilateral transactions. This is due to the fact that the bilateral transactions have been taken additional to the pool transactions and with these additional transactions the power flow patterns changes and generators schedule changes to accommodate additional bilateral transactions.

The marginal cost comparison for real power at few buses for both the cases are shown in the Figs. 9 and 10 for both pool and bilateral models without and with SVC.

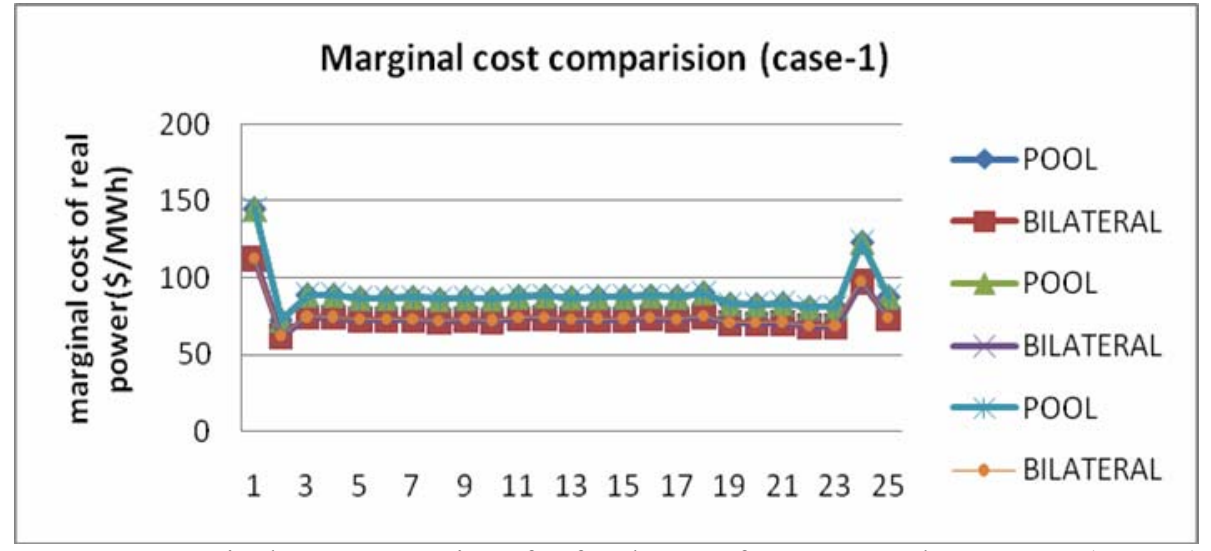

Figure 9. Marginal cost comparison for few buses of NREG-246 bus system (Case-1)

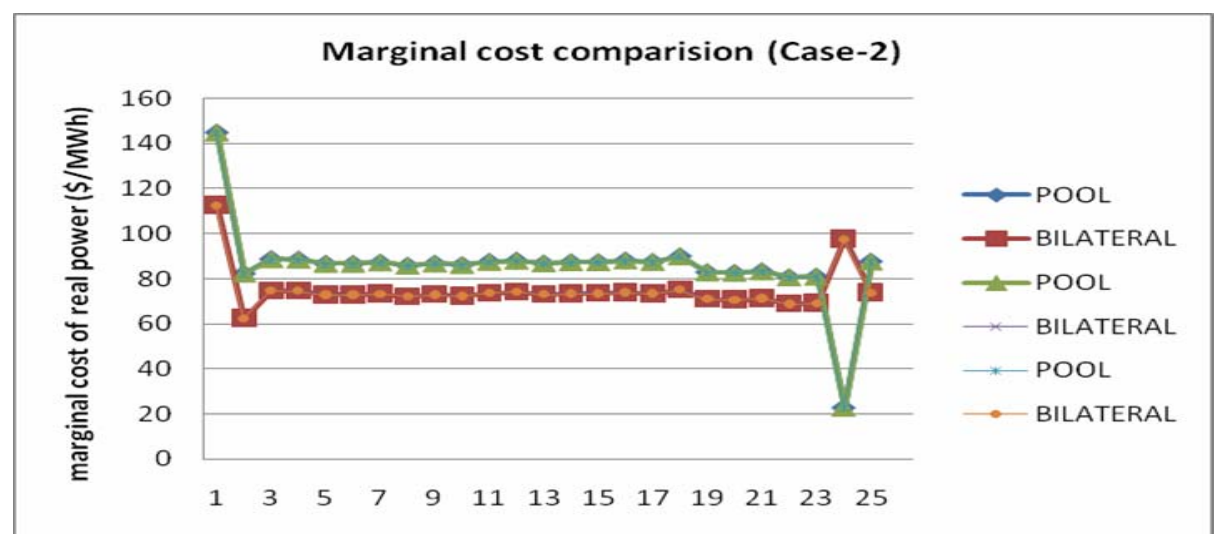

Figure 10. Marginal cost comparison at few buses for NREG-246 bus system (Case-2)

Based on the marginal cost comparison, it is found that the marginal prices of real power at buses are lower for bilateral model compared to pool model for both the cases. This can be attributed to the change in the pattern of power flows due to the additional bilateral transactions. The curves for marginal cost are overlapping for different reactive cost model methods as marginal prices obtained are almost same at each bus. The marginal prices of real power at few buses for pool and hybrid market model are given in Table 5 and Table 6 for both the cases. As observed from Table 5, the marginal prices are similar at all the buses and there is little change in the marginal prices comparing all the methods. The impact of SVC can be observed at some of the buses considerably. It is observed that SVC has considerable impact on the marginal prices as these reduce at each bus for both the cases. For hybrid market model, the marginal prices at each bus are found lower due to the change in the patterns of the line flows with additional bilateral transactions. 
Table 5. Marginal prices results at few buses for NREG-246 bus system

\begin{tabular}{|c|c|c|c|c|c|}
\hline & Method-1 & & Method-2 & & Method-3 \\
\hline POOL & BILATERAL & POOL & BILATERAL & POOL & BILATERAL \\
\hline 144.8021 & 112.8501 & 144.8021 & 112.8501 & 144.8021 & 112.8501 \\
\hline 72.371 & 62.3676 & 72.371 & 62.3676 & 72.371 & 62.3676 \\
\hline 88.8005 & 74.7623 & 88.8005 & 74.7623 & 88.8005 & 74.7623 \\
\hline 88.5822 & 74.6604 & 88.5822 & 74.6604 & 88.5822 & 74.6604 \\
\hline 86.7273 & 72.9655 & 86.7273 & 72.9655 & 86.7273 & 72.9655 \\
\hline 86.7273 & 72.9655 & 86.7273 & 72.9655 & 86.7273 & 72.9655 \\
\hline 87.2786 & 73.3891 & 87.2786 & 73.3891 & 87.2786 & 73.3891 \\
\hline 85.8943 & 72.1554 & 85.8943 & 72.1554 & 85.8943 & 72.1554 \\
\hline 86.7826 & 73.0206 & 86.7826 & 73.0206 & 86.7826 & 73.0206 \\
\hline 86.2181 & 72.4188 & 86.2181 & 72.4188 & 86.2181 & 72.4188 \\
\hline 87.6176 & 73.7196 & 87.6176 & 73.7196 & 87.6176 & 73.7196 \\
\hline 88.1304 & 74.1767 & 88.1304 & 74.1767 & 88.1304 & 74.1767 \\
\hline 86.8859 & 73.053 & 86.8859 & 73.053 & 86.8859 & 73.053 \\
\hline 87.3827 & 73.4698 & 87.3827 & 73.4698 & 87.3827 & 73.4698 \\
\hline 87.4593 & 73.5305 & 87.4593 & 73.5305 & 87.4593 & 73.5305 \\
\hline 88.2086 & 74.0009 & 88.2086 & 74.0009 & 88.2086 & 74.0009 \\
\hline 87.6657 & 73.4426 & 87.6657 & 73.4426 & 87.6657 & 73.4426 \\
\hline 90.1125 & 75.1364 & 90.1125 & 75.1364 & 90.1125 & 75.1364 \\
\hline 82.8538 & 70.9566 & 82.8538 & 70.9566 & 82.8538 & 70.9566 \\
\hline 82.5389 & 70.6622 & 82.5389 & 70.6622 & 82.5389 & 70.6622 \\
\hline 83.2873 & 71.3324 & 83.2873 & 71.3324 & 83.2873 & 71.3324 \\
\hline 80.5355 & 68.7928 & 80.5355 & 68.7928 & 80.5355 & 68.7928 \\
\hline 80.8604 & 69.0434 & 80.8604 & 69.0434 & 80.8604 & 69.0434 \\
\hline 123.037 & 97.737 & 123.037 & 97.737 & 123.037 & 97.737 \\
\hline 87.6669 & 73.8127 & 87.6669 & 73.8127 & 87.6669 & 73.8127 \\
\hline
\end{tabular}

Table 6. Results for NREG-246 bus system (Case-2)

\begin{tabular}{|c|c|c|c|c|c|}
\hline \multicolumn{2}{|c|}{ Method-1 } & \multicolumn{2}{c|}{ Method-2 } & \multicolumn{2}{c|}{ Method-3 } \\
\hline POOL & BILATERAL & POOL & BILATERAL & POOL & BILATERAL \\
\hline 144.6227 & 112.8101 & 144.6227 & 112.8101 & 144.6227 & 112.1529 \\
\hline 2.2692 & 62.3031 & 62.2692 & 62.3031 & 62.2692 & 62.2365 \\
\hline 8.6945 & 74.6978 & 8.6945 & 74.6978 & 8.6945 & 74.5480 \\
\hline 8.4831 & 74.5996 & 8.4831 & 74.5996 & 8.4831 & 74.4477 \\
\hline 6.6319 & 72.9106 & 6.6319 & 72.9106 & 6.6319 & 72.7553 \\
\hline 6.6319 & 72.9106 & 6.6319 & 72.9106 & 6.6319 & 72.7553 \\
\hline 7.1803 & 73.3323 & 7.1803 & 73.3323 & 7.1803 & 73.1771 \\
\hline 5.7934 & 72.0981 & 5.7934 & 72.0981 & 5.7934 & 71.9461 \\
\hline 86.7118 & 72.9862 & 86.7118 & 72.9862 & 86.7118 & 72.8113 \\
\hline 86.1099 & 72.3552 & 86.1099 & 72.3552 & 86.1099 & 72.2082 \\
\hline 87.5314 & 73.6721 & 87.5314 & 73.6721 & 87.5314 & 73.5078 \\
\hline
\end{tabular}


Table 6. (cont'd) Results for NREG-246 bus system (Case-2)

\begin{tabular}{|c|c|c|c|c|c|}
\hline \multicolumn{2}{|c|}{ Method-1 } & \multicolumn{2}{c|}{ Method-2 } & \multicolumn{2}{c|}{ Method-3 } \\
\hline POOL & BILATERAL & POOL & BILATERAL & POOL & BILATERAL \\
\hline 88.0407 & 74.1258 & 88.0407 & 74.1258 & 88.0407 & 73.9640 \\
\hline 86.7939 & 73.0014 & 86.7939 & 73.0014 & 86.7939 & 72.8421 \\
\hline 87.2902 & 73.4174 & 87.2902 & 73.4174 & 87.2902 & 73.2578 \\
\hline 87.3648 & 73.4765 & 87.3648 & 73.4765 & 87.3648 & 73.3182 \\
\hline 88.0870 & 73.9268 & 88.0870 & 73.9268 & 88.0870 & 73.7819 \\
\hline 87.4887 & 73.3222 & 87.4887 & 73.3222 & 87.4887 & 73.2223 \\
\hline 89.9632 & 75.0435 & 89.9632 & 75.0435 & 89.9632 & 74.8929 \\
\hline 82.9071 & 70.8883 & 82.9071 & 70.8883 & 82.9071 & 70.7768 \\
\hline 82.6159 & 70.6015 & 82.6159 & 70.6015 & 82.6159 & 70.4796 \\
\hline 83.3386 & 71.2654 & 83.3386 & 71.2654 & 83.3386 & 71.1526 \\
\hline 80.6629 & 68.8202 & 80.6629 & 68.8202 & 80.6629 & 68.6327 \\
\hline 80.9790 & 69.0641 & 80.9790 & 69.0641 & 80.9790 & 68.8817 \\
\hline 22.9366 & 97.7317 & 22.9366 & 97.7317 & 22.9366 & 97.2083 \\
\hline 87.5879 & 73.7706 & 87.5879 & 73.7706 & 87.5879 & 73.6017 \\
\hline
\end{tabular}

\section{Conclusions}

In this work, nodal price for real and reactive power have been obtained taking reactive power cost model for generators' reactive support into account. FACTS devices viz. SVC with its cost model has been incorporated in the model to find the impact of SVC on nodal price at each bus. The following conclusions can be expressed as:

(i) The total cost has been obtained minimum using method 3 .

(ii) The cost component of reactive power is obtained minimum using method 3.

(iii) The cost component of SVC is obtained minimum for method 1.

(iv) With SVC, the reactive power nodal prices reduce at all buses due to its reactive support. There is also reduction in the cost of real power price at each node however marginal due to the reactive power support.

(v) For hybrid market model, the marginal prices are found lower at all buses compared to pool model due to the change in flow patterns with additional bilateral transactions over and above pool transactions.

It is observed that reactive power cost component is an important element to be considered for nodal price determination and overall cost computation of transmission services. The FACTS devices can be remunerated based on the cost component obtained for their reactive support in the system.

\section{Nomenclature}

$N_{g} \quad$ Set of generators

$P_{g i} \quad$ Active power pool generator- $i$

$\mathrm{C}_{\mathrm{i}} \quad$ Fuel cost of pool generator- $i$

$a_{g i}, b_{g i}, c_{g i} \quad$ Cost coefficients in $\$ / \mathrm{h}, \$ / \mathrm{MWh}, \$ / \mathrm{MWh}^{2}$

$P_{i} \quad$ Real power injection at bus $-i$;

$Q_{i} \quad$ Reactive power injection at bus- $i$;

$P_{g i}, Q_{g i} \quad$ Real and reactive power generation at bus- $i$;

$I_{a} \quad$ Armature current of generator

$P_{d i}, Q_{d i} \quad$ Real and reactive power demand at bus- $i$;

$V i \quad$ Voltage magnitude at bus- $i$;

$\delta_{i} \quad$ Voltage angle at bus- $i$;

$Y_{i j}=G_{i j}+B_{i j} \quad i$-jth element of Y-bus matrix;

$N_{b} \quad$ Number of buses in the system;

$N_{d} \quad$ Number of load buses;

$P_{g i}^{\min }, P_{g i}^{\max } \quad$ Minimum and maximum real power generation limit; 


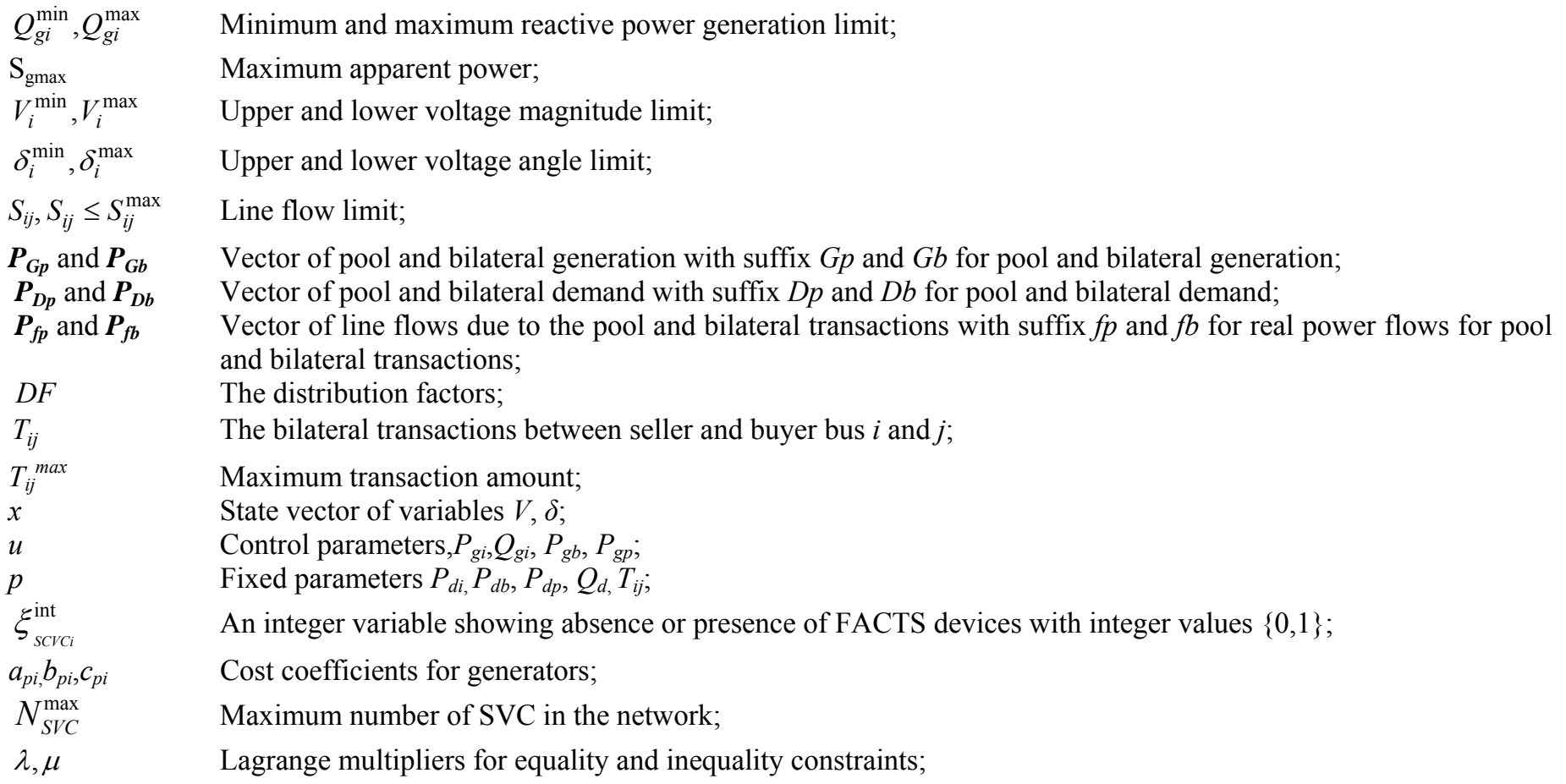

\section{References}

Baughman, M. L. and Siddiqi, S. N., 1993. Real time pricing of reactive power: Theory and case study results. IEEE Trans. on Power Systems, Vol. 6, No. 1, pp. 23-29.

Bajpai, P. and Singh, S. N., 2006 .An electric power trading model for Indian electricity market. in Proc. IEEE PES, PIC, pp. 1-5.

Cai, L. J., and Erlich, István, Optimal choice and allocation of FACTS devices using genetic algorithms, 2003 .ISAP, Intelligent Systems Application to Power Systems, Lemnos, Greece, August 31 - September 3.

Chattopadhyaya, D., Bhattacharya, K., and Parikh, J., 1995. Optimal reactive power planning and its spot pricing: An integrated approach. IEEE Trans. on Power Systems, Vol. 10, No. 4, pp. 2014-2019.

Chanana, S. and Kumar, A., "Effects of optimally located FACTS devices on active and reactive power prices in deregulated electricity markets", in Proc. IEEE PIC, New Delhi, 2006.

Chanana, S. and Kumar, A., 2010 .Marginal price of active and reactive power in hybrid electricity markets. Journal of CBIP, Jan 2010.

Cheng, J.W.M., Galiana, F.D., and McGills, D.T., 1998 .Studies of bilateral contracts with respect to steady state security in a deregulated environment. IEEE Trans. on Power systems, Vol. 13, No. 3, pp. 1020-1025.

Choi, J. Y., Rim, S., and Park, J., 1998. Optimal real time pricing of real and reactive powers, IEEE Trans. on Power Systems, Vol. 13, No. 4, pp. 1226-1231.

Dandachi, N. H., Rawlins, M., Alsac, O., Paris, M., and Stott, B., 1996 .OPF for reactive power transmission pricing on the NGC system. IEEE Trans. on Power Systems, Vol. 11, No. 1, pp. 226-232.

Dai, Y., Ni, Y. X., Wen, F. S., and Han, Z. X., 2000. Analysis of reactive power under deregulation. in Proc. IEEE PES, pp. 21622167.

de Olivera E. J., Lima J. W. M., and Pereira, J. L. R., 1999 .Flexible AC transmission devices: Allocation and transmission pricing. Electric Power and Energy systems, Vol.21, pp. 111-118.

Dona, V. M. and Paredes, A. N., 2001 .Reactive power pricing in competitive electric markets using transmission losses function. in Proc. IEEE Porto Power Tech. Conf. 10-13 ${ }^{\text {th }}$ Sept.

El-Keib, A. A., and Ma, X., 1997. Calculating the short-run marginal costs of active and reactive power production, IEEE Trans. on Power Systems, Vol. 12, No. 2, pp. 559-565.

GAMS - The Solver Manuals, 2001 .GAMS Development Corporation, March 2001.

Gill J. B., Roman, T. G. S., Rioa, J. J. A., and Martin, P. S., 2000. Reactive power pricing: A conceptual framework for remuneration and charging procedures. IEEE Trans. on Power Systems, Vol. 15, No. 2, pp. 483-489.

Hao, S. and Pepalexopolous, A.,1997. A reactive power pricing and management, IEEE Trans. on Power Systems. Vol. 12, No. 1, pp 95-104.

Hamoud, G., 2000 .Feasibility assessment of simultaneous bilateral transactions in a deregulated environment. IEEE Trans. on Power systems, Vol. 15, No. 1, pp. 22-26. 
Lamont, J. W., and Fu. J., 1999 .Cost analysis of reactive power support. IEEE Trans. on Power Systems, Vol. 14, No. 3, pp. 890898.

Li, Y. Z. and David, A. K., 1993 .Wheeling rates of reactive flow under marginal cost theory. IEEE Trans. on Power Systems, Vol. 10, No. 3, Aug. 1993.

MATLAB and GAMS: 1999 .Interfacing Optimization and Visualization Software. Michael C. Ferris, August 10.

Muchayi, M. and El-Hawary, M. E., 1999 .A summary of algorithms in reactive power pricing. Electric Power and System Research, Vol. 21, pp. 119-124.

Paucar, V. L., and Rider, M. J., 2001 .Reactive power pricing in deregulated electrical markets using methodology based on theory of marginal costs. in Proc. IEEE PES General Meeting.

Parida, S. K., Srivastava, S. C., and Singh, S. N., 2009 .An approach to promote frequency regulation service in India. Int. Jour. on Energy Sector Management, Emerald, pp. 6-23.

Parida, S. K., 2009 .Road map to develop ancillary service model for Indian Electricity Industry scenario. Power management Institute, NTPC.

Rider, M. J. and Paucar, M. L., 2004 .Application of nonlinear reactive power pricing model for competitive electric markets. IEE Proc. Generation, Transmission, Distribution, Vol. 151, No. 3, pp. 407-414.

Srivastava, S. C. and Verma, R. K., 2000 .Impact of FACTS devices on transmission pricing in a deregulated market. in Proc. Int. Conf. on Electric Utility Deregulation and Restructuring and Power Technologies, DRPT, London, 4-7, pp. 642-648.

Singh, S.N., Verma, K.S., and Gupta, H.O., 2001 .Optimal power flow control in open power market using unified power flow controller. IEEE Power Engineering Society Summer Meeting, 15-19 July.

Singh, S. N. and David, A. K., 2000 .Placement of FACTS devices in open power market in Proc. 5th conference on advances in power system control, operation and management, APSCOM, pp. 173-177, Hong Kong, Oct.

Singh, S. N. and Srivastava, S. C., 2004 .Electric Power Industry restructuring in India: Present Scenario and future prospect. in Proc. DRPT, Hong Kong, April, pp. 20-23.

Sharma, A. K., 2007. New secure bilateral transaction matrix determination using AC distribution factors and impact of TCPAR and TCSC on its pattern. Electric Power Components and Systems, Vol. 35, pp. 21-943.

Shrestha, G. B. and Feng, W., 2005. Effects of series compensation on spot price markets, Electric Power and Energy Systems. Vol. 27, pp. 428-436.

Zhao, Y., Irving, M. R., and Song, Y., 2005 .A cost allocation and pricing method for reactive power services in the new deregulated electricity market environment. in Proc. IEEE Transmission and Distribution Conference, Asia and Pacific, Dalian, China, pp 1-6.

\section{Biographical notes}

A. Kumar received B. Tech. in electrical engineering from G. B. Pant University of Agri. and Technology, Pant nagar in 1988, M. E. in Power Systems from Punjab University, Chandigarh in 1994 in honors and Ph.D. from Indian Institute of Technology Kanpur, India in 2003, respectively. He is an Assoc. Professor in the Department of Electrical Engineering, National Institute of Technology Kurukshetra, India. His research interests include power system restructuring, power system dynamics, renewable energy, demand side management, and distributed generation. He is a life member of IE (India), ISTE (India), and member of IEEE/IEEE PES.

Punit Kumar did his masters in power systems from Department of Electrical Engineering, National Institute of Technology Kurukshetra, India. He joined Rajasthan state electricity board as an assistant engineer. He has interest in power system restructuring and power system operation.

Received December 2010

Accepted March 2011

Final acceptance in revised form April 2011 